Pacific Journal of Mathematics

SOME NEW RESULTS ON ODD PERFECT NUMBERS

G. DADA PA, JOHN L HUNSUCKER AND CARL POMERANCE 


\title{
SOME NEW RESULTS ON ODD PERFECT NUMBERS
}

\author{
G. G. Dandapat, J. L. Hunsucker and \\ Carl Pomerance
}

\begin{abstract}
If $m$ is a multiply perfect number $(\sigma(m)=t m$ for some integer $t$ ), we ask if there is a prime $p$ with $m=p^{a} n$, $\left(p^{a}, n\right)=1, \sigma(n)=p^{a}$, and $\sigma\left(p^{a}\right)=t n$. We prove that the only multiply perfect numbers with this property are the even perfect numbers and 672 . Hence we settle a problem raised by Suryanarayana who asked if odd perfect numbers necessarily had such a prime factor. The methods of the proof allow us also to say something about odd solutions to the equation $\sigma(\sigma(n))=2 n$.
\end{abstract}

1. Introduction. In this paper we answer a question on odd perfect numbers posed by Suryanarayana [17]. It is known that if $m$ is an odd perfect number, then $m=p^{a} k^{2}$ where $p$ is a prime, $p \nmid k$, and $p \equiv a \equiv 1(\bmod 4)$. Suryanarayana asked if it necessarily followed that

$$
\sigma\left(k^{2}\right)=p^{a}, \quad \sigma\left(p^{a}\right)=2 k^{2} .
$$

Here, $\sigma$ is the sum of the divisors function. We answer this question in the negative by showing that no odd perfect number satisfies (1).

We actually consider a more general question. If $m$ is multiply perfect $(\sigma(m)=t m$ for some integer $t)$, we say $m$ has property $S$ if there is a prime $p$ with $m=p^{a} n,\left(p^{a}, n\right)=1$, and the equations

$$
\sigma(n)=p^{a}, \quad \sigma\left(p^{a}\right)=t n
$$

hold. Note that if $n, p, a, t$ is a solution of (2) with $p$ prime, then $1=\left(p^{a}, \sigma\left(p^{a}\right)\right)=\left(p^{a}, n\right)$, so that $\sigma\left(p^{a} n\right)=t p^{a} n$; that is $p^{a} n$ is multiply perfect. Hence the multiply perfect numbers with property $S$ are in one-to-one correspondence with the solutions of (2). We shall prove:

THEOREM 1. If $p$ is a prime, $n, a, t$ are positive integers, and (2) holds, then either

$$
n=21, \quad p=2, a=5, \quad t=3
$$

or

$$
n=2^{k}, \quad p=2^{k+1}-1, \quad a=1, \quad t=2 .
$$

COROLLARY. If $m$ is a multiply perfect number with property 
$S$, then $m=672$ or $m$ is an even perfect number. In particular, no odd perfect number has property $S$.

Write the odd perfect number $m=p^{a} k^{2}$ as a product of primes $p^{a} p_{1}^{2 a_{1}} \cdots p_{\iota}^{2 a \nu}$. (Note that Pomerance [12] and Robbins [14] have shown that $\nu \geqq 6$.) Let $N(m)$ be the number of subscripts $i$ for which there is a subscript $j$ such that $\left(\sigma\left(p_{i}^{2 a} p_{j}^{2 a}\right), p_{i} p_{j}\right)>1$. Then $0 \leqq N(m) \leqq \nu$. It is not difficult to see that Suryanarayana's equations (1) are equivalent to the odd perfect $m$ satisfying $N(m)=0$. Hence the above corollary implies $N(m)>0$. We show however that $N(m)$ is not even close to 0 , but more nearly $\nu$.

THOREM 2. If $m$ is an odd perfect number, then

$$
\nu+1-[\log (\nu+1) / \log 2] \leqq N(m) \leqq \nu .
$$

Several authors (Kanold [8], Niederreiter [11], Suryanarayana [16], [18]) have considered the equation

$$
\sigma(\sigma(n))=2 n,
$$

calling the solutions $n$ super perfect. The even super perfects have been completely classified, but it is not known if any odd super perfects exist. The methods we develop to consider (1), (2), and (5) allow us also to get some results on odd solutions of (6). We shall prove:

THEOREM 3. If $n$ is an odd super perfect number, then neither $n$ nor $\sigma(n)$ is a prime power and either $n$ or $\sigma(n)$ is divisible by at least 3 distinct primes.

Note that Suryanarayana [18] has already shown that $n$ is not a prime power, but we give a new proof here for completeness. We (the second and third authors) have actually been able to prove much more than Theorem 3, but we do not give the details in this paper. (We have proved that if $n$ is an odd super perfect number, then $n>7 \cdot 10^{24}, \omega(n \sigma(n)) \geqq 5$, and $\omega(n)+\omega(\sigma(n)) \geqq 7$. Here $\omega(n)$ is the number of distinct prime factors of $n$.)

The main tool of this paper (Theorem A in $\S 2$ ) has the remarkable distinction of having been proved independently nine times.

In the research for this paper, the first author worked separately from the other authors.

2. Preliminaries. If $x, y$ are integers, we shall write $x \| y$ if $x \mid y$ and $(x, y / x)=1$. If $p, q$ are distinct primes, we shall denote by $\operatorname{ord}_{q}(p)$ the exponent $p$ belongs to $\bmod q$, that is, the smallest 
natural number $d$ for which $p^{d} \equiv 1(\bmod q)$. We denote by $a_{q}(p)$ the integer $e$ such that $q^{e} \| p^{d}-1$, where $d=\operatorname{ord}_{q}(p)$. Clearly $\operatorname{ord}_{q}(p) \mid q-1$ and $a_{q}(p) \geqq 1$.

From Theorems 94 and 95 in Nagell [10] and the fact that $\sigma\left(p^{x}\right)=\left(p^{x+1}-1\right) /(p-1)$, we have:

LEMMA 1. Suppose $p, q$ are distinct primes with $q \neq 2$ and $b, c$ are natural numbers. Then

(i) if $p \equiv 1(\bmod q)$, then $q^{b} \| \sigma\left(p^{c}\right)$ if and only if $q^{b} \| c+1$,

(ii) if $p \not \equiv 1(\bmod q)$, then $q^{b} \| \sigma\left(p^{c}\right)$ if and only if $b \geqq a_{q}(p)$, $\operatorname{ord}_{q}(p) \mid c+1$, and $q^{b-a_{q}(p)} \| c+1$.

Lemma 2. Suppose $p, q$ are distinct primes, $x, y, b, c$ are natural numbers, $\sigma\left(q^{x}\right)=p^{y}$ and $q^{b} \| \sigma\left(p^{c}\right)$. Assume $q \neq 2$. Then

(i) if $p \equiv 1(\bmod q)$, then $q^{b} \| c+1$,

(ii) if $p \not \equiv 1(\bmod q)$, then $\operatorname{ord}_{q}(p) \mid c+1$ and $q^{b-1} \| c+1$.

Proof. Now (i) follows from (i) of Lemma 1. Also (ii) will follow from (ii) of Lemma 1 provided we show $a_{q}(p)=1$. Now $p^{y}=\sigma\left(q^{x}\right)=1+q+\cdots+q^{x}$, so that $p^{y}-1 \equiv q\left(\bmod q^{2}\right)$. Then since $p \not \equiv 1(\bmod q)$, we have $q \|\left(p^{y}-1\right) /(p-1)=\sigma\left(p^{y-1}\right)$. Lemma 1 now implies $a_{q}(p)=1$.

There is a well-known result about expressions of the form $\left(a^{b}-1\right) /(a-1)$ (see Bang [2], Zsigmondy [20], Sylvester [19], Birkhoff and Vandiver [3], Dickson [4], Kanold [7], Artin [1], Leopoldt [9], Richter [13]), which implies the following:

THEOREM A. If $p$ is a prime, $x$ is a natural number, and $1<d \mid x+1$, then there is a prime $q \mid \sigma\left(p^{x}\right)$ with ord $_{q}(p)=d$, unless

(i) $p=2$ and $d=6$,

(ii) $p$ is a Mersenne prime (that is, of the form $2^{k}-1$ ) and $d=2$.

3. The main results. In this section we prove Theorems 1 and 2 .

Proof of Theorem 1. We first consider the case $p=2$. From the equation $\sigma(n)=2^{a}$ and Theorem $\mathrm{A}$, we see that $n$ is a product of distinct Mersenne primes (cf. Sierpiński [15]); say $n=p_{1} p_{2} \cdots p_{s}$ where each $p_{i}=2^{k_{i}}-1, k_{i}$ is prime and $k_{1}<k_{2}<\cdots<k_{s}$. Then $a=\sum k_{i}$. Now $t n=\sigma\left(2^{a}\right)=2^{1+\sum k_{i}}-1$. Hence for $1 \leqq j \leqq s$, we have $2^{k_{j}}-1 \mid 2^{1+\Sigma k_{i}}-1$, so that $k_{j} \mid \sum k_{i}$. Since the $k_{j}$ are distinct primes, we have 


$$
\prod_{i=1}^{8} k_{i} \mid 1+\sum_{i=1}^{8} k_{i}
$$

Then $s \geqq 2$. Now the expression $\Pi k_{i}-1-\sum k_{i}$ increases separately in each of the $s$ "variables" $k_{1}, k_{2}, \cdots, k_{s}$. If $s=2, k_{1}=2, k_{2}=3$, we have $2 \cdot 3 \mid 1+2+3$. This gives the solution (3). If $s=2$ and $k_{2} \geqq 5$, then $k_{1} k_{2}-1-k_{1}-k_{2} \geqq 2 \cdot 5-1-2-5>0$, so that (7) fails. Also if $s \geqq 3, \Pi k_{i}-1-\sum k_{i}>2^{s}-1-2 s>0$, so again (7) fails.

We now consider the case $p>2$. Since $\sigma(n)=p^{a}$ is odd, we have $n=2^{k} p_{1}^{2 a_{1}} \cdots p_{r}^{2 a}$, where $k \geqq 0, r \geqq 0$, and $p_{1}, \cdots, p_{r}$ distinct odd primes. Suppose $r=0$, so that $n=2^{k}$. Then $\sigma(n)=2^{k+1}-1=p^{a}$. Suppose $a>1$. By Theorem A, there is a prime $q \mid \sigma\left(p^{2 a-1}\right)$ with $\operatorname{ord}_{q}(p)=2 a$. Then $q \mid\left(p^{2 a}-1\right) /\left(p^{a}-1\right)=p^{a}+1=2^{k+1}$, an impossibility since $q$ is odd (cf. Gerono [6]). Hence $a=1$ and we have solution (4). Thus we may assume $r \geqq 1$. Now for $1 \leqq i \leqq r$, we have $\sigma\left(p_{i}^{2 a_{i}}\right) \mid p^{a}$ and $p_{i}^{2 a_{i}} \mid \sigma\left(p^{a}\right)$. Lemma 2 then implies $p_{i} \mid a+1$, so that $p_{1} p_{2} \cdots p_{r} \mid a+1$. Theorem A implies there is a prime $q \mid \sigma\left(p^{a}\right)$ with $\operatorname{ord}_{q}(p)=p_{1} p_{2} \cdots p_{r}$. Then $q \neq 2, p_{1}, \cdots, p_{r}$, and since $q \mid t n$, we have $q \mid t$. Hence

$$
\begin{aligned}
p_{1} p_{2} \cdots p_{r}<q \leqq t= & \frac{\sigma\left(p^{a}\right)}{n}=\frac{\sigma\left(p^{a}\right)}{p^{a}} \cdot \frac{\sigma(n)}{n} \\
= & \frac{p^{a+1}-1}{p^{a}(p-1)} \cdot \frac{2^{k+1}-1}{2^{k}} \cdot \Pi \frac{p_{i}^{2 a_{i}+1}-1}{p_{i}^{2 a_{i}}\left(p_{i}-1\right)} \\
& <\frac{p}{p-1} \cdot 2 \cdot \Pi \frac{p_{i}}{p_{i}-1},
\end{aligned}
$$

so that

$$
1<\frac{2 p}{p-1} \cdot \Pi \frac{1}{\left(p_{i}-1\right)} \leqq \frac{2 p}{(p-1)\left(p_{1}-1\right)} \leqq \frac{2 \cdot 3}{2 \cdot 4}<1,
$$

a contradiction.

Proof of Theorem 2. If $i$ is such that $1 \leqq i \leqq \nu$ and $\left(\sigma\left(p_{i}^{2 a_{i}} p_{j}^{2 a j}\right)\right.$, $\left.p_{i} p_{j}\right)=1$ for all $j, 1 \leqq j \leqq \nu$, then $p_{i}^{2 a_{i}} \mid \sigma\left(p^{a}\right)$ and $\sigma\left(p_{i}^{2 a_{i}}\right) \mid p^{a}$. Let $\Omega$ be the set of such subscripts $i$, and let $\omega$ be the cardinality of $\Omega$. Lemma 2 implies that $\Pi_{\Omega} p_{i} \mid a+1$. Since also $2 \mid a+1$, we have at least $2^{\omega+1}-1$ divisors $d$ of $a+1$ with $d>1$. Since $p$ is not a Mersenne prime (we have $p \equiv 1(\bmod 4))$, Theorem $\mathrm{A}$ implies for each such $d$, there is a prime $r=r_{d} \mid \sigma\left(p^{a}\right)$ with $\operatorname{ord}_{r}(p)=d$. Then each $r_{d}$ is odd, and since $m$ is perfect, we have $r_{d} \in\left\{p_{1}, p_{2}, \cdots, p_{\nu}\right\}$. Hence $2^{\omega+1}-1 \leqq \nu$, so that $\omega \leqq[\log (\nu+1) / \log 2]-1$. 


\section{Super perfect numbers.}

Lemma 3. Let $n$ be an odd super perfect number. Then

(i) $n$ is a square,

(ii) $\sigma(n)$ is odd,

(iii) the prime factorization of $\sigma(n)$ is $p^{a} p_{1}^{2 a_{1}} \cdots p_{\nu}^{2 a_{\nu}}$ where $p \equiv a \equiv 1(\bmod 4)$ and $\nu \geqq 0$.

Proof. Kanold [8] proved (i) and (ii). Then $m=\sigma(n)$ is an odd integer for which $2 \| \sigma(m)$. Then such an odd integer must have the prime factorization indicated in (iii) (cf. Euler [5]).

Proof of Theorem 3. Suppose $\sigma(n)$ is the prime power $p^{a}$. Then $\sigma\left(p^{a}\right)=\sigma(\sigma(n))=2 n$, so that Theorem 1 implies $p^{a} n$ is even, contradicting Lemma 3.

Suppose $n$ is the prime power $q^{b}$. Then, in the notation of Lemma 3 , we have just proved that $\nu \geqq 1$, so that for $1 \leqq i \leqq \nu$ we have $p_{i}^{2 a_{i}} \mid \sigma\left(q^{b}\right)$ and $\sigma\left(p_{i}^{2 a_{i}}\right) \mid q^{b}$. Say $r=\max \left\{p_{1}, p_{2}, \cdots, p_{\nu}\right\}$. Now Lemma 2 implies either $r^{2} \mid b+1$ or $r \cdot \operatorname{ord}_{r}(q) \mid b+1$ in which case $\operatorname{ord}_{r}(q)>1$. In the first case $b+1$ has the 2 divisors $r$ and $r^{2}$ which are multiples of $r$. In the second case, $b+1$ has the 2 divisors $r$ and $r \cdot \operatorname{ord}_{r}(q)$ which are multiples of $r$. Since $q$ is odd, in either case Theorem A implies there are 2 distinct primes dividing $\sigma\left(q^{b}\right)$ which are $1(\bmod r)$. This contradicts (iii) of Lemma 3 and the choice of $r$.

Suppose both $n$ and $\sigma(n)$ are divisible by precisely 2 distinct primes. Now if $(n, \sigma(n))=1$, then $n \sigma(n)$ is divisible by precisely 4 distinct primes and $\sigma(n \sigma(n))=\sigma(n) \sigma(\sigma(n))=2 n \sigma(n)$. Then Lemma 3 implies $n \sigma(n)$ is an odd perfect number. This contradicts the previously stated result ([12], [14]) that every odd perfect number is divisible by at least 7 distinct primes. Hence $(n, \sigma(n))>1$. Hence from Lemma 3 we have the prime factorizations

$$
\begin{aligned}
n & =q^{2 b} r^{2 c} \\
\sigma(n) & =q^{\alpha} s^{\beta} .
\end{aligned}
$$

Now $\sigma\left(q^{2 b}\right) \mid s^{\beta}$ and since $n \mid \sigma(\sigma(n))$, we have $q^{2 b} \mid \sigma\left(s^{\beta}\right)$. Then, as in the above paragraph, there are at least 2 distinct primes dividing $\sigma\left(s^{\beta}\right)$ which are $1(\bmod q)$. This contradicts $\sigma\left(s^{\beta}\right) \mid 2 n$.

\section{REFERENCES}

1. E. Artin, The orders of the linear groups, Comm. Pure Appl. Math., VIII (1955), 355-366.

2. A. S. Bang, Taltheoretiske Unders $\phi$ gelser, Tidsskrift Math. 5 IV (1886), 70-80 and 130-137. 
3. G. D. Birkhoff and H. S. Vandiver, On the integral divisors of $a^{n}-b^{n}$, Ann. of Math., 5 (1904), 173-180.

4. L. E. Dickson, On the cyclotomic function, Amer. Math. Monthly, 12 (1905), 8689.

5. L. Euler, Tractatus de Numerorum Doctrina, Commentationes Arithmeticae Collectae, 2 (1849), 514.

6. C. G. Gerono, Note sur la résolution en nombres entiers et positifs de l'équation $x^{m}=y^{n}+1$, Nouv. Ann. Math., (2) 9 (1870), 469-471, 10 (1871), 204-206.

7. H.-J. Kanold, Satze über Kreisteilungspolynome und ihre Anwendungen auf einige zahlentheoretische Probleme, I, J. Reine Angew. Math., 187 (1950), 169-182.

8. — Über "Super perfect numbers", Elem. Math., 24 (1969), 61-62.

9. H. W. Leopoldt, Lösung einer Aufgabe von Kostrikhin, J. Reine Angew. Math., 221 (1966), 160-161.

10. T. Nagell, Introduction to Number Theory, Chelsea Publ. Co., New York, 1964.

11. H. G. Niederreiter, Solution of Aufgabe 601, Elem. Math., 25 (1970), 66-67.

12. C. Pomerance, Odd perfect numbers are divisible by at least seven distinct primes, Acta Arith., 25 (1974), 265-300.

13. B. Richter, Die Primfaktorzerlegung der Werte der Kreisteilungspolynome, J. Reine Angew. Math., 254 (1972), 123-132.

14. N. Robbins, The non-existence of odd perfect numbers with less than seven distinct prime factors, doctoral dissertation at the Polytechnic Institute of Brooklyn, June, 1972.

15. W. Sierpiński, Sur les nombres dont la somme des diviseurs est un puissance du nombre 2, The Golden Jubile Commemoration Volume (1958-9), Calcutta Math. Soc., 7-9.

16. D. Suryanarayana, Super perfect numbers, Elem. Math., 24 (1969), 16-17.

17. - Problems in theory of numbers, Bull. Amer. Math. Soc., 76 (1970), 977.

18. - There is no odd super perfect number of the form $p^{2 \alpha}$, Elem. Math., 28 (1973), 148-150.

19. J. J. Sylvester, On the divisors of the sum of a geometrical series whose first term is unity and common ratio any positive or negative integer, Nature XXXVII (1888), 417-418.

20. K. Zsigmondy, Zur Theorie der Potenzreste, Monatshefte Math. Phys., 3 (1892), 265-284.

Received October 16, 1974

INDIAN INSTITUTE OF TECHNOLOGY

AND

UNIVERSITY OF GEORGIA 


\section{PACIFIC JOURNAL OF MATHEMATICS}

\section{EDITORS}

RICHARD ARENS (Managing Editor)

University of California

Los Angeles, California 90024

\section{J. DugundJI}

Department of Mathematics University of Southern California Los Angeles, California 90007

D. Gilbarg and J. Milgram

Stanford University

Stanford, California 94305
University of Washington Seattle, Washington 98105

\section{ASSOCIATE EDITORS}
E. F. BECKENBACH
B. H. NeumanN
F. WolF
K. YoShIDA

\section{SUPPORTING INSTITUTIONS}

\author{
UNIVERSITY OF SOUTHERN CALIFORNIA \\ STANFORD UNIVERSITY \\ UNIVERSITY OF TOKYO \\ UNIVERSITY OF UTAH \\ WASHINGTON STATE UNIVERSITY \\ UNIVERSITY OF WASHINGTON \\ $\stackrel{*}{*} \stackrel{*}{*} \stackrel{*}{ }{ }^{*}$ AMERICAN MATHEMATICAL SOCIETY
}

The Supporting Institutions listed above contribute to the cost of publication of this Journal, but they are not owners or publishers and have no responsibility for its content or policies.

Mathematical papers intended for publication in the Pacific Journal of Mathematics should be in typed form or offset-reproduced, (not dittoed), double spaced with large margins. Underline Greek letters in red, German in green, and script in blue. The first paragraph or two must be capable of being used separately as a synopsis of the entire paper. Items of the bibliography should not be cited there unless absolutely necessary, in which case they must be identified by author and Journal, rather than by item number. Manuscripts, in triplicate, may be sent to any one of the editors. Please classify according to the scheme of Math. Reviews, Index to Vol. 39. All other communications should be addressed to the managing editor, or Elaine Barth, University of California, Los Angeles, California, 90024.

The Pacific Journal of Mathematics expects the author's institution to pay page charges, and reserves the right to delay publication for nonpayment of charges in case of financial emergency.

100 reprints are provided free for each article, only if page charges have been substantially paid. Additional copies may be obtained at cost in multiples of 50 .

The Pacific Journal of Mathematics is issued monthly as of January 1966. Regular subscription rate: $\$ 72.00$ a year (6 Vols., 12 issues). Special rate: $\$ 36.00$ a year to individual members of supporting institutions.

Subscriptions, orders for back numbers, and changes of address should be sent to Pacific Journal of Mathematics, 103 Highland Boulevard, Berkeley, California, 94708.

\section{PUBLISHED BY PACIFIC JOURNAL OF MATHEMATICS, A NON-PROFIT CORPORATION}

Printed at Kokusai Bunken Insatsusha (International Academic Printing Co., Ltd.), 270, 3-chome Totsuka-cho, Shinjuku-ku, Tokyo 160, Japan.

\section{Copyright (C) 1975 by Pacific Journal of Mathematics} Manufactured and first issued in Japan 


\section{Pacific Journal of Mathematics}

\section{Vol. 57, No. $2 \quad$ February, 1975}

Norman Larrabee Alling, On Cauchy's theorem for real algebraic curves with boundary .......

Daniel D. Anderson, A remark on the lattice of ideals of a Prüfer domain ..................

Dennis Neal Barr and Peter D. Miletta, A necessary and sufficient condition for uniqueness of

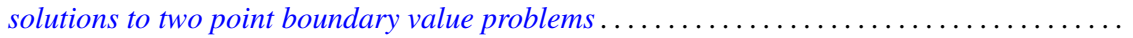

Ladislav Beran, On solvability of generalized orthomodular lattices . . . . . . . . . . ........

L. Carlitz, A three-term relation for some sums related to Dedekind sums . . . . . . . . . .....

Arthur Herbert Copeland, Jr. and Albert Oscar Shar, Images and pre-images of localization

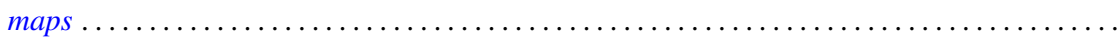

G. G. Dandapat, John L. Hunsucker and Carl Pomerance, Some new results on odd perfect

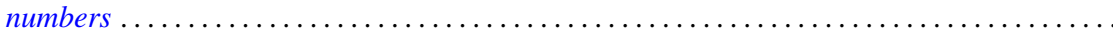

M. Edelstein and L. Keener, Characterizations of infinite-dimensional and nonreflexive

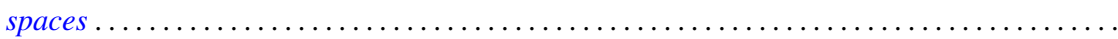

Francis James Flanigan, On Levi factors of derivation algebras and the radical embedding

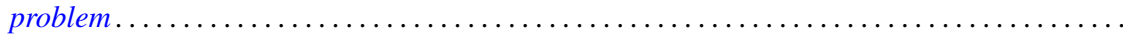

Harvey Friedman, Provable equality in primitive recursive arithmetic with and without

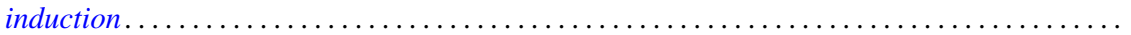

Joseph Braucher Fugate and Lee K. Mohler, The fixed point property for tree-like continua with



John Norman Ginsburg and Victor Harold Saks, Some applications of ultrafilters in



Arjun K. Gupta, Generalisation of a "square" functional equation .....................

Thomas Lee Hayden and Frank Jones Massey, Nonlinear holomorphic semigroups ..........

V. Kannan and Thekkedath Thrivikraman, Lattices of Hausdorff compactifications of a locally

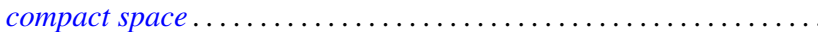

J. E. Kerlin and Wilfred Dennis Pepe, Norm decreasing homomorphisms between group



Young K. Kwon, Behavior of $\Phi$-bounded harmonic functions at the Wiener boundary ...

Richard Arthur Levaro, Projective quasi-coherent sheaves of modules .

Chung Lin, Rearranging Fourier transforms on groups...........................

David Lowell Lovelady, An asymptotic analysis of an odd order linear differential equation . . 4475

Jerry Malzan, On groups with a single involution .......................... 481



Carl Pomerance, On multiply perfect numbers with a special property .

Mohan S. Putcha and Adil Mohamed Yaqub, Polynomial constraints for finiteness of semisimple rings. .

Calvin R. Putnam, Hyponormal contractions and strong power convergence . . . . . . . . . 531

Douglas Conner Ravenel, Multiplicative operations in $\mathrm{BP} * \mathrm{BP} \ldots \ldots \ldots \ldots \ldots \ldots \ldots \ldots \ldots .539$

Judith Roitman, Attaining the spread at cardinals which are not strong limits . . . . . . . . . 545

Kazuyuki Saitô, Groups of *-automorphisms and invariant maps of von Neumann algebras . . . 553

Brian Kirkwood Schmidt, Homotopy invariance of contravariant functors acting on smooth

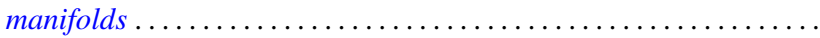

Kenneth Barry Stolarsky, The sum of the distances to $N$ points on a sphere.

Mark Lawrence Teply, Semiprime rings with the singular splitting property.

J. Pelham Thomas, Maximal connected Hausdorff spaces..............

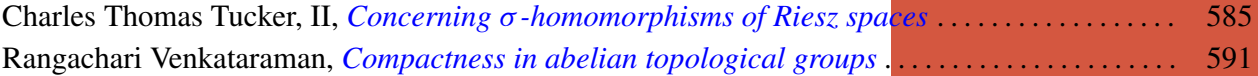

William Charles Waterhouse, Basically bounded functors and flat sheaves . . . . . . . . . . . 597

David Westreich, Bifurcation of operator equations with unbounded linearized part ......... 611

William Robin Zame, Extendibility, boundedness and sequential convergence in spaces of 